\title{
Percepções de estudantes do curso técnico em agropecuária sobre o uso de fertilizantes no semiárido
}

Os diferentes conhecimentos expressos sobre o uso de fertilizantes químicos e orgânicos estão intimamente ligados à formação dos agricultores e profissionais que atuam no campo. Este estudo teve como objetivo analisar o conhecimento dos estudantes do curso Técnico Integrado em Agropecuária do Instituto Federal de Educação, Ciência e Tecnologia do Rio Grande do Norte, campus de Apodi (RN) sobre a utilização de fertilizantes, químicos e orgânicos, na região do semiárido. Para tanto, foram aplicados questionários estruturados para estudantes do curso mencionado nesse campus. Posteriormente, as respostas foram analisadas e categorizadas em seis grupos: Supridores artificiais das necessidades do solo; Uso de fertilizantes sem critério técnico; Fertilizantes prejudiciais à saúde; Fertilizantes agressores do meio ambiente; Adubação orgânica benéfica ao solo; Ênfase Sustentável. Grande parte dos entrevistados acreditava que os fertilizantes químicos são usados para correção e nutrição do solo, trazendo benefícios para a produção, mas podem causar doenças e problemas ambientais, sobretudo em elevadas quantidades. Além disso, os estudantes também acreditam que a adubação orgânica traz inúmeros benefícios, sobretudo por ser natural. Os discentes entrevistados consideram que, tanto os fertilizantes químicos quanto os orgânicos, são importantes para suprir as necessidades do solo, contudo os orgânicos se destacaram por serem mais rentáveis e mais sustentáveis.

Palavras-chave: Percepção; Fertilizantes químicos; Adubação orgânica.

\section{Perceptions of agricultural technical students about the use of fertilizers in the semiarid}

\begin{abstract}
The different knowledge expressed about the use of chemical and organic fertilizers is closely linked to the training of farmers and professionals working in the field. This study aimed to analyze the knowledge of the students of the Integrated Technical Course in Agriculture of the Federal Institute of Education, Science and Technology of Rio Grande do Norte, Apodi campus (RN) about the use of fertilizers, chemical and organic, in the region of. semiarid. To this end, structured questionnaires were applied to students of the course mentioned on this campus. Subsequently, the responses were analyzed and categorized into six groups: Artificial supply of soil needs; Fertilizer use without technical criteria; Health harmful fertilizers; Environmentally aggressive fertilizers; Beneficial organic fertilization to the soil; Sustainable Emphasis. Most respondents believed that chemical fertilizers are used for soil correction and nutrition, bringing benefits to production, but can cause disease and environmental problems, especially in large quantities. In addition, students also believe that organic fertilization has numerous benefits, especially because it is natural. The students interviewed consider that both chemical and organic fertilizers are important to meet the needs of the soil, but organic ones stood out for being more profitable and more sustainable.
\end{abstract}

Keywords: Perception; Chemical fertilizers; Organic fertilization.

Topic: Desenvolvimento, Sustentabilidade e Meio Ambiente

Reviewed anonymously in the process of blind peer
Received: 08/10/2018

Approved: 08/11/2018
Allyne do Nascimento Eufrásio Silva

Universidade Federal do Rio Grande do Norte, Brasil

http://lattes.cnpq.br/0550309219697361

allyne_16eufrasio@hotmail.com

Sueli Aparecida Moreira (iD

Universidade Federal do Rio Grande do Norte

http://lattes.cnpq.br/9469781068838287

http://orcid.org/0000-0002-0558-5808

suelimoreira@yahoo.com.br

Elaine Cristina do Nascimento Rodrigues

Universidade Federal do Rio Grande do Norte, Brasil

http://lattes.cnpq.br/1545766433106164

elainecristina.rn@gmail.com
Juliana Espada Lichston (iD

Universidade Federal do Rio Grande do Norte, Brasil

http://lattes.cnpq.br/0727435909982933

http://orcid.org/0000-0002-4042-4524

j.lichston@gmail.com
Referencing this:

SILVA, A. N. E.; MOREIRA, S. A.; RODRIGUES, E. C. N.; LICHSTON, J. E.. Percepções de estudantes do curso técnico em agropecuária sobre o uso de fertilizantes no semiárido. Revista lbero-Americana de Ciências Ambientais, v.9, n.8, p.168-177, 2019. DOI:

http://doi.org/10.6008/CBPC2179-6858.2018.008.0015 


\section{INTRODUÇÃO}

Com o crescimento da população mundial, a agricultura sofreu diversas mudanças passando de um sistema mais rústico, em que os 'agricultores' utilizavam áreas de cultivo naturais sem adição de pesticidas, agrotóxicos e maquinaria pesada, para uma agricultura mais complexa utilizando esses insumos. $\mathrm{O}$ avanço do conhecimento tecnológico na área agrícola, sobretudo no que diz respeito aos insumos químicos, a agricultura moderna deixou de considerar os fenômenos naturais e passou a utilizar os mecanismos desse novo modo de cultivar a terra (ASSIS et al., 2002), proporcionando uma agricultura intensiva capaz de produzir em grandes proporções cereais de grãos, leguminosas de grãos, hortícolas e forragens (PEDROJUNIOR, 2015), carecendo cada vez mais de agentes que fossem capazes de suprir as necessidades e demandas das práticas agrícolas.

A partir desse momento, surge a necessidade de estudar compostos que promovam a manutenção do solo e favoreçam o desenvolvimento dos cultivares. Mazoyer et al. (2010) destaca que os adubos ou fertilizantes são substâncias minerais ou orgânicas, que quando incorporadas ao solo, fornecem nutrientes e outros compostos, tais como hormônios de crescimento, necessários para que as plantas consigam completar seu ciclo de vida.

Além disso, são responsáveis pela obtenção de boa produção agrícola (PEDRO-JUNIOR, 2015), e em grandes regiões de produção, tanto nos Estados Unidos, quanto na União Europeia, atingem níveis elevados de produção graças ao desenvolvimento tecnológico e utilização de adubos. No entanto, Camargo (2012) afirma que para que isso ocorra é importante que os nutrientes estejam em quantidades adequadas às diversas culturas vegetais existentes. Caso haja ausência do fornecimento de nutrientes, pelos fertilizantes, as plantas os absorverão das reservas do solo, e esse mecanismo pode causar esgotamento reduzindo a quantidade de matéria orgânica, que além de ofertar nutrientes, contribui também para melhorar a retenção de hídrica no solo (CAMARGO, 2012).

A demanda de serviços e produtos pela sociedade vem se destacando desde muito tempo. No entanto, essa exigência esboçou-se com maior importância no início da Revolução Industrial, no século XVIII, acentuando-se nos séculos posteriores (JARDIM et al., 2009). De acordo com Vieites (2010), no início, a adubação química começou a ser praticada devido às descobertas do químico alemão Justus Von Liebig, por volta do século XIX, que substituiu a fertilização natural, com base nas rotações de culturas e pelo esterco animal, tornando o processo de produção menos complexo, apenas adicionando a substância, poupando tempo e mão de obra e aumentando a produtividade das lavouras.

Contudo, este tipo de fertilização deve ser acompanhado e realizado de forma correta, pois pode promover perdas dos componentes através da liberação de substâncias para o meio, e dessa forma ocasionar vários prejuízos ao ambiente (PEDRO-JUNIOR, 2015). A grande demanda, produção e utilização de produtos químicos pela sociedade tem gerado como consequência o acúmulo desses compostos no meio ambiente (JARDIM et al., 2009) sobretudo no solo, quando compromete os recursos hídricos, tanto os que estão presentes no subsolo, quanto os corpos hídricos superficiais (COSTA et al., 2017). 
Será que os colaboradores que trabalham na agricultura têm consciência sobre os impactos ambientais que podem ser causados pelo uso indiscriminado dos fertilizantes? Por esse motivo, faz-se necessária a investigação a respeito do que os profissionais em formação na área agrária sabem sobre o uso dos fertilizantes. Com isso, o presente estudo objetiva analisar as percepções expressas por jovens estudantes do curso de Ensino Técnico Integrado em Agropecuária do IFRN campus Apodi (RN) sobre a utilização de fertilizantes, químicos e orgânicos, na região do Semiárido nordestino.

\section{MATERIAIS E MÉTODOS}

Trata-se de estudo transversal de natureza qualitativa, cuja abordagem se deu em forma de enquete. Este tipo de abordagem "[...] lida com grande número de informantes com objetivos definidos a respeito da informação/opinião que se quer obter dos sujeitos entrevistados" (MAKSENAS, 2002). Optou-se pela pesquisa de natureza qualitativa porque ela busca responder a questões muito particulares em um nível de realidade que não pode ser quantificado, através das interpretações das realidades sociais (BAUER et al., 2002).

A aplicação dos questionários foi realizada em novembro de 2017 , tendo como público alvo estudantes de três turmas do ensino técnico integrado do curso de Agropecuária do Instituto Federal de Educação, Ciência e Tecnologia do Rio Grande do Norte, campus de Apodi (RN). No total, 92 discentes participaram da pesquisa, e foram enumerados do 1 ao 92, com o intuito de facilitar a referência a eles na discussão dos resultados e preservar o anonimato.

Para a coleta dos depoimentos foi utilizado um questionário semiestruturado composto por 6 questões discursivas. De posse das respostas dos estudantes, as questões foram analisadas qualitativamente. A análise dos dados consistiu na leitura das respostas dos estudantes, acerca de questões sobre a prática do uso de fertilizantes químicos e orgânicos pelos agricultores da região de Apodi (RN). Tais respostas trouxeram aproximações de como estes indivíduos enxergam o uso do solo e as práticas agrícolas da região em que eles vivem.

Os dados dos 92 questionários respondidos pelos estudantes foram analisados e emergiram seis grupos de respostas que foram distribuídas nas seguintes categorias: Supridores artificiais das necessidades do solo; Uso de fertilizantes sem critério técnico; Fertilizantes prejudiciais à saúde; Fertilizantes agressores do meio ambiente; Adubação orgânica benéfica ao solo; Ênfase à sustentabilidade.

Quanto aos aspectos éticos para a realização dessa pesquisa, com base na Resolução do Conselho Nacional de Saúde CNS/MS nำ510, de 07 de abril de 2016 para garantir a livre participação, os dados foram coletados mediante assinatura do Termo de Consentimento Livre e Esclarecido autorizado pela escola e com o assentimento dos jovens. 


\section{RESULTADOS E DISCUSSÃO}

\section{Perfil dos entrevistados}

Do total de estudantes, que responderam ao questionário, se encontram numa faixa etária entre 15 a 23 anos. Quanto ao gênero 56 indivíduos eram do sexo feminino e 36 do sexo masculino. Observou-se também que a maior parte dos discentes 78 disseram que tinham parentes agricultores, e apenas 14 afirmaram não ter, conforme observado na figura 1.

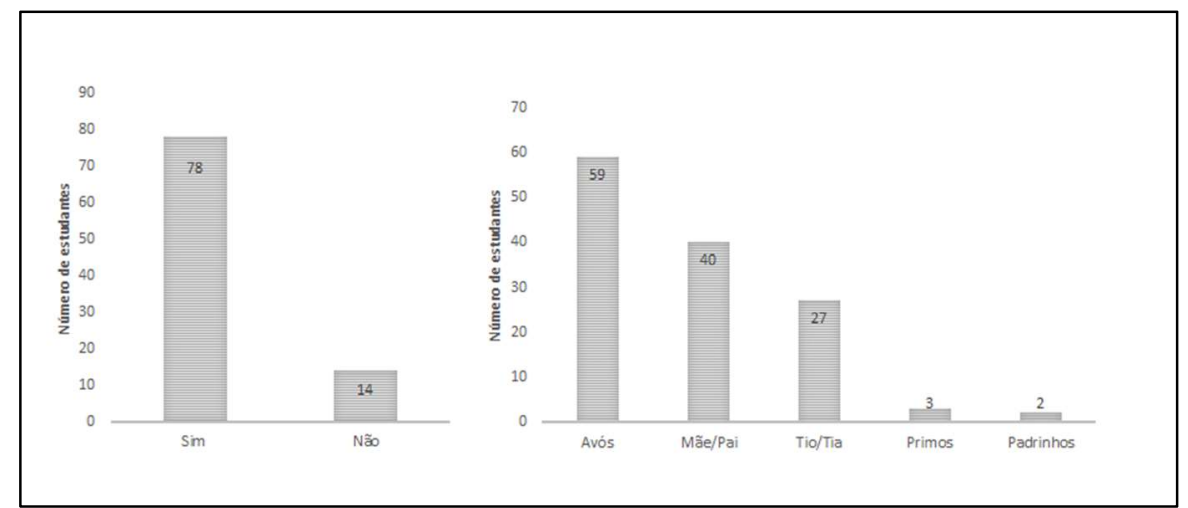

Figura 1: Fonte de informação de estudantes do curso técnico em agropecuária do IFRN Apodi/RN relacionada à situação familiar.

Os familiares são as primeiras fontes de conhecimento dos estudantes. Dessen et al. (2007) afirma que a família é a primeira mediadora entre o homem e a cultura e é responsável por constituir as relações afetivas, social e cognitivas, além disso, é caracterizada como o centro da aprendizagem humana que gera significados e práticas culturais próprias. A maioria dos estudantes tinha, pelo menos, um familiar agricultor sendo os mais citados o pai, a mãe, a avó, o avô, o tio, a tia, os primos e padrinhos. Notou-se que a maioria dos entrevistados expressou conhecimento prévio relacionado aos assuntos abordados na pesquisa desde a 1a série do ensino médio integrado.

\section{Uso de fertilizantes na percepção de estudantes}

Na percepção discente, o uso de fertilizantes químicos e orgânicos remetia aos aspectos tanto positivos, quanto negativos. Termos, tais como, artificial, danosa ao meio ambiente, combate de pragas, agressora do solo, desenvolvedora de doenças, faz mal à saúde, correção do solo, baixo custo, auxilia no desenvolvimento de plantas, natural, sustentável, utilização do solo fértil por mais tempo, corresponderam às diversas opiniões que os alunos associavam ao uso dos fertilizantes químicos e orgânicos.

Com base nas percepções desses estudantes, podemos dizer que essas formas de fertilizar o solo trazem benefícios e malefícios, tanto para o agricultor, quando faz o uso desses produtos, se expondo aos químicos e aumentando o valor dos insumos utilizados na plantação, ou para o meio ambiente, que, em excesso, provoca a contaminação das reservas de água e acarreta também deterioração ao solo. Neste contexto, é comum encontrar discursos que favorecem apenas um lado, que os fertilizantes químicos são apenas ruins, porque trazem prejuízos ao meio ambiente e do outro que os adubos orgânicos são apenas 
benéficos porque são naturais. Segundo Morales et al. (2012), a adubação, quando realizada com a matéria orgânica é benéfica, pois diminui as chances de lixiviação e contaminação, pois os nutrientes são liberados gradativamente, sem prejuízos ao solo. Para Santos et al. (2015), a utilização do adubo químico causa prejuízo a fertilidade do solo principalmente ao longo do tempo.

Assim, foi possível observar que quando questionados acerca do que sabiam sobre fertilização química do solo, na maioria das respostas os estudantes acreditavam que os fertilizantes químicos são os supridores artificiais das necessidades do solo. No entanto, alguns estudantes acreditam que estas substâncias também podem ser nocivas ao meio ambiente. Nesta categoria estão inseridas as respostas que indicam que os fertilizantes são produtos químicos, portanto, artificiais, que auxiliam no suprimento de nutrientes para o solo, mas que também podem ocasionar diversos tipos de danos, principalmente se usado de forma inadequada. As respostas abaixo no quadro 1 evidenciam esta visão dos jovens.

Quadro 1. Opiniões de estudantes destacando os fertilizantes como supridores artificias das necessidades do solo.

\begin{tabular}{|c|c|}
\hline Entrevistados & Expressões utilizadas \\
\hline Estudante 4 & 'Uma fertilização que obviamente é feita artificial e que se usos abusivos forem feitos será prejudicial'. \\
\hline Estudante 7 & $\begin{array}{l}\text { 'Feita com vários produtos químicos para ajudar o solo se desenvolver, porém o uso excessivo da fertilização } \\
\text { acaba prejudicando o solo e acabando com a vida que há naquele solo, e é quando aumentamos a fertilidade do } \\
\text { solo'. }\end{array}$ \\
\hline Estudante 80 & $\begin{array}{l}\text { 'Usando em uma quantidade necessária pode trazer alguns benefícios, mas também malefícios com o uso em } \\
\text { excesso'. }\end{array}$ \\
\hline Estudante 10 & $\begin{array}{l}\text { 'Que ocorre através da utilização de produtos químicos para fazer com que o solo produza mais e com maior } \\
\text { qualidade'. }\end{array}$ \\
\hline Estudante 10 & $\begin{array}{l}\text { 'É quando com o uso de produtos químicos adicionamos qualidades suficientes para o solo receber culturas } e \\
\text { sustentá-los seu potencial produtivo aumenta. }\end{array}$ \\
\hline Estudante 69 & $\begin{array}{l}\text { 'O uso dos fertilizantes químicos que são incorporados ao solo para melhorar e fortalecer a qualidade da } \\
\text { produção'. }\end{array}$ \\
\hline Estudante 90 & 'É a incorporação de produtos químicos no solo para transformá-lo em solo produtivo'. \\
\hline Estudante 22 & 'Ajudam no crescimento de plantas'. \\
\hline Estudante 44 & $\begin{array}{l}\text { 'A fertilização química serve para repor os nutrientes em pouca concentração no solo, isso de forma que ofereça } \\
\text { o nutriente necessário com a quantidade recomendada'. }\end{array}$ \\
\hline Estudante 47 & $\begin{array}{l}\text { 'A fertilidade química do solo é a utilização de produtos químicos no solo com o intuito de apresentar um rápido } \\
\text { desenvolvimento ou uma maneira mais prática de elevar, porém não faz bem nem a saúde e nem ao meio } \\
\text { ambiente'. }\end{array}$ \\
\hline
\end{tabular}

Nas informações ressaltadas pelos discentes, os fertilizantes químicos têm a função de enriquecer o solo e com isso suprir as necessidades que ele precisa fornecer às plantas que serão cultivadas. E ainda que as plantas tenham um bom desenvolvimento, essa prática deve ser realizada com cautela, para que se possa evitar o comprometimento do solo e dos serviços realizados por ele. Esta visão também é encontrada no trabalho de Camargo (2012), de que os fertilizantes são os principais responsáveis pelo suprimento de nutrientes do solo fazendo com que as culturas cultivadas consigam se desenvolver melhor. De fato, os fertilizantes são importantes para manter uma boa produtividade nas lavouras, muitos pesquisadores evidenciaram positivamente a adubação em culturas de interesse comercial informando ter melhorado os dados de produção (VÉRAS et al., 2015; PINHEIRO et al., 2017; SOUSA et al., 2017; ROMUALDO et al., 2018).

Uso do fertilizante sem critério técnico também se fez presente em grande parte das respostas dos estudantes quando questionados se haviam presenciado algum agricultor utilizar fertilizante químico e se este foi orientado por algum profissional da área. A maioria dos estudantes respondeu que não tinha conhecimento sobre o uso de fertilizantes por parte dos agricultores na região. Porém, quanto aos 
estudantes que responderam ter ouvido falar do uso dos fertilizantes químicos, informaram que os agricultores utilizam o produto, porque esses obtiveram alguma informação de como utilizá-lo (quadro 2). Seja por meio de conhecimento trazido por um profissional, como técnico ou agrônomo ou pela indicação de outros colegas agricultores ou de avós, tios, pais que usaram. Podemos ver as situações explicativas desta ideia nas afirmativas propostas.

Quadro 2: Informação de estudantes acerca da percepção do uso de fertilizantes por agricultores.

\begin{tabular}{|c|c|}
\hline Entrevistados & Falas dos estudantes \\
\hline Estudante 12 & 'Nunca parei para me informar, mas com certeza sim'. \\
\hline Estudante 4 & $\begin{array}{l}\text { 'Sim, ele utilizou porque outros agricultores mostravam ter eficiência no cultivo, mas não foi orientado por } \\
\text { nenhum'. }\end{array}$ \\
\hline Estudante 34 & $\begin{array}{l}\text { 'Já soube de pessoas que usaram sim, meu pai, ele não usou equipamentos certos ou de segurança e não foi } \\
\text { orientado por profissional'. }\end{array}$ \\
\hline Estudante 45 & $\begin{array}{l}\text { 'Já, como os agricultores veem passando de geração para geração seus conhecimentos vêm da família, então } \\
\text { provavelmente ele está utilizando dos conhecimentos familiares'. }\end{array}$ \\
\hline Estudante 60 & $\begin{array}{l}\text { 'Já sim, pelo meu pai que planta melancia, arroz e outras culturas, muitas vezes ele utiliza por já saber outras } \\
\text { recomendações'. }\end{array}$ \\
\hline Estudante 63 & 'Sim, utilizou. Acredito que não foi orientada, apenas por experiências vividas, etc.'. \\
\hline Estudante 66 & $\begin{array}{l}\text { 'Com certeza a maioria dos agricultores da região usa adubos químicos. Pela maioria dos produtores serem de } \\
\text { uma geração mais velha, acredito que começaram a usar por conta própria, sem orientação técnica anterior'. }\end{array}$ \\
\hline
\end{tabular}

Na pesquisa realizada por Rodrigues et al. (2015), foram observadas divergências, quanto à necessidade e a aplicação de fertilizantes, relacionado à falta de técnicos para orientação no trabalho de campo. Fato este que pode acontecer em qualquer outra propriedade, tendo em vista que uma orientação profissional é de suma importância, tanto para a utilização do adubo químico, quanto para a ausência deste, mas principalmente para saber como realizar os procedimentos com segurança. Além disso, mesmo que a adubação seja feita de forma mais natural, ou seja, utilizando o adubo orgânico, também se faz necessária a orientação de um profissional qualificado, pois os resíduos orgânicos podem ocasionar diversos impactos ao meio ambiente, dentre os quais, a eutrofização de corpos hídricos, sobretudo em regiões que pouca disponibilidade de água (FINATTO et al., 2013).

A perspectiva de os fertilizantes serem prejudiciais à saúde foi unanime. Além disso, esses problemas estão intimamente ligados ao uso inadequado, a dosagem do produto e a falta de orientação. 0 conhecimento sobre o uso do fertilizante em excesso causar danos à saúde foi a resposta mais frequente, pois compreendeu a opinião de 4 estudantes (quadro 3). Nesse sentido, a percepção dos discentes com relação aos fertilizantes aparece em respostas como as que seguem.

Quadro 3: Percepções de estudantes acerca de algum reconhecimento sobre prejuízos a saúde em consequência do uso de fertilizantes.

\begin{tabular}{|c|l|}
\hline $\begin{array}{c}\text { Entrevistados } \\
\text { Estudantes } 7,78, \\
85 \text { e } 90\end{array}$ & 'Sim o uso do fertilizante em excesso pode prejudicar a saúde'. \\
\hline Estudante 1 & 'Sim, mas só será prejudicial se o agricultor não utilizar direito'. \\
\hline Estudante 67 & 'Sim e não, depende da maneira que o agricultor estar usando'. \\
\hline Estudante 9 & $\begin{array}{l}\text { 'Sim. Alguns fertilizantes tem um alto teor de substâncias, substâncias essas que fazem em excesso a } \\
\text { contaminação de alimentos e água, que quando consumidos causam mal à saúde sim'. }\end{array}$ \\
\hline Estudante 74 & 'Sim, pois sem o cuidado necessário, os produtos podem deixarem parte na fruta que iremos consumir'. \\
\hline Estudante 20 & 'Eu acredito que sim, se for usado de maneira errada'. \\
\hline Estudante 84 & 'Sim, depende da qualidade do fertilizante e a quantidade utilizada'. \\
\hline Estudante 54 & 'A má dosagem de fertilizantes químicos, podem causar danos futuros a saúde'. \\
\hline Estudante 59 & 'Sim, acredito. Pois trazem em sua composição moléculas cancerígenas e prejudiciais'. \\
\hline
\end{tabular}


Nesta perspectiva é possível observar que os estudantes, enquanto futuros profissionais da área sabem que a utilização desses produtos pode ser danosa à saúde tanto do trabalhador, atualmente, quanto pode provocar problemas posteriores, nas próximas gerações. Abreu et al. (2014) constatou que quando se trata de insumos agrícolas, mesmo realizando todos os procedimentos de segurança, ainda assim os trabalhadores estão sujeitos a contaminação com esses produtos.

Alguns sujeitos que participaram desta pesquisa responderam que os fertilizantes químicos podem ser Agressores do meio ambiente, quando questionados se eles acreditavam que os fertilizantes poderiam trazer algum prejuízo ao meio ambiente. Na visão deles, estes produtos, caso usados em pequenas ou grandes quantidades, podem ser levados pelo vento e atingir rios, lagos, o lençol freático, contaminando alimento, os animais e as plantações vizinhas. Como exemplo de respostas, temos o quadro 4.

Quadro 4: Visão dos estudantes quanto aos prejuízos que os fertilizantes químicos podem trazer ao meio ambiente.

\begin{tabular}{|c|l|}
\hline Entrevistados & \multicolumn{1}{c|}{ Expressões utilizadas } \\
\hline 2 & $\begin{array}{l}\text { 'Sim, após a utilização dos fertilizantes, passam os ventos e levam muito dos produtos utilizados para os rios, } \\
\text { lagoas, etc. Assim infectando a água que será consumida por animais e até mesmo por humanos'. }\end{array}$ \\
\hline Estudante 10 & 'Sim, pois há vários relatos de poluição de rios, plantas e etc.". \\
\hline Estudante 53 & 'Sim, pois podem ser tóxicos a algumas espécies'. \\
\hline Estudante 66 & 'Com certeza, principalmente com o uso excessivo no solo e poluindo as águas, e até os animais'. \\
\hline Estudante 73 & 'Sim, e até mesmo prejudicar outras plantações vizinhas'. \\
\hline Estudante 5 & 'Eu creio que sim, sem uma orientação profissional'. \\
\hline Estudante 21 & 'Sim, com o uso excessivo ou sem prática para a aplicação'. \\
\hline Estudante 41 & $\begin{array}{l}\text { '[...] Fertilizantes naturais serão sempre a melhor maneira de ter um solo bom, os fertilizantes químicos trazem } \\
\text { desgastes ao solo, tornando o mesmo desgastado". }\end{array}$ \\
\hline Estudante 85 & 'Quando usados em grandes quantidades, sim, pois causam prejuízos residuais'. \\
\hline Estudante 92 & $\begin{array}{l}\text { 'Sim, o solo perderá cada vez mais os seus nutrientes. E como dito, em pequenas quantidades, nem tudo é } \\
\text { problema'. }\end{array}$ \\
\hline
\end{tabular}

De acordo aos relatos dos estudantes podemos perceber que foi comum o pensamento de que os fertilizantes químicos podem causar alguma agressão ao meio ambiente. Esse resultado confirma o estudo de revisão de Almeida-Neto et al. (2017), cujo levantamento bibliográfico reportou uma preocupação em vários trabalhos quanto ao uso de insumos agrícolas, sobretudo, agrotóxicos que causam a contaminação principalmente dos recursos hídricos, escassos em algumas regiões, e que também traz efeitos negativos à saúde humana, gerando problemas de saúde que podem levar os indivíduos até a morte.

Quando os estudantes foram questionados se sabiam sobre o uso da fertilização orgânica na região surge a categoria Benéfica ao solo, nesse sentido a adubação é considerada como um meio de fornecer nutrientes para o solo, entretanto fazendo uso dos próprios componentes da natureza, sem a necessidade de adicionar substâncias 'estranhas' que pode ocasionar danos futuros. As informações obtidas sobre este tipo de adubação foram em alguns casos passadas pelas gerações anteriores de agricultores. Stamato et al. (2017) afirma que as metodologias de participação onde há trocas de conhecimentos, sejam eles científico ou agrário é característico de novas correntes da prática na agricultura. Assim, as respostas no quadro 5, demonstram os benefícios em utilizar a fertilização orgânica.

A adubação orgânica é uma alternativa viável de acordo com a pesquisa de Sediyama et al. (2016) cujos benefícios foram de grande potencial, e além disso contribui na redução dos impactos negativos 
gerados pelo descarte indevido de resíduos orgânicos no meio ambiente. A ênfase na sustentabilidade foi o termo mais frequentemente usado pelos estudantes quando foram questionados se durante a prática profissional eles indicariam o uso da adubação orgânica aos agricultores. Dessa forma, é possível acreditar que os estudantes percebiam o uso da adubação orgânica como um instrumento capaz de fazer com que a agricultura seja permanente ou exista o mais tempo possível.

Quadro 5: Percepção dos estudantes sobre o uso da adubação orgânica na região em que vivem.

\begin{tabular}{|c|c|}
\hline Entrevistados & Falas dos discentes \\
\hline Estudante 9 & $\begin{array}{l}\text { 'Sim, a adubação orgânica é indicação por que é de baixo custo e simples de realizar, pode ser com restos } \\
\text { orgânicos que incorporados ao solo a deixam mais nutrido e sem desgastes. É muito mais viável'. }\end{array}$ \\
\hline Estudante 53 & $\begin{array}{l}\text { 'Não. Acho que é a melhor adubação, pois vai haver um ciclo mutuo em que vamos usar de artifícios do meio } \\
\text { ambiente e vamos retornar esses artifícios para ser adubo de plantações. Também é uma boa alternativa pois } \\
\text { enriquece o solo de maneira natural e tem um bom custo'. }\end{array}$ \\
\hline Estudante 72 & $\begin{array}{l}\text { 'Já sim; são reaproveitáveis e não existe gastos altos quanto a compra de produtos, por exemplo, a palha da } \\
\text { carnaúba'. }\end{array}$ \\
\hline Estudante 23 & $\begin{array}{l}\text { 'Sim, pois essas matérias orgânicas que são incorporadas ao solo vão se decompor deixando assim o solo mais } \\
\text { fértil'. }\end{array}$ \\
\hline Estudante 88 & $\begin{array}{l}\text { 'Sim, adubação orgânica traz vários benefícios para o ambiente dessa forma aproveitando até restos das outras } \\
\text { colheitas anteriores. }\end{array}$ \\
\hline Estudante 11 & $\begin{array}{l}\text { 'Tem várias vantagens, pois a adubação orgânica é uma maneira boa para o meio ambiente e também } \\
\text { sustentável'. }\end{array}$ \\
\hline Estudante 83 & 'Sim, os benefícios são que ajudam a preservar o meio ambiente'. \\
\hline Estudante 34 & 'Não presenciei, mas os benefícios são inúmeros, só em evitar problemas de saúde, e prejudicar menos o solo'. \\
\hline Estudante 45 & $\begin{array}{l}\text { 'Minha avó utiliza, acho que é a melhor coisa a se fazer, pois é menos prejudicial à saúde, aos animais e } \\
\text { principalmente ao nosso querido solo'. }\end{array}$ \\
\hline Estudante 65 & $\begin{array}{l}\text { 'A adubação orgânica pode ajudar de muitas formas, como material morto protegendo o solo dos raios solares, } \\
\text { deixando o solo mais fértil para o plantio entre outros'. }\end{array}$ \\
\hline
\end{tabular}

Leff (2009) afirma que "o saber ambiental muda o olhar do conhecimento e com isso transforma as condições do saber no mundo na relação que estabelece o ser com o pensar e o saber, com o conhecer e o atuar no mundo". Nesse sentido, esta afirmação de Leff ilustra que quando os sujeitos se formam com a visão diferente sobre o meio ambiente e os problemas ambientais, essa formação refletirá também no desenvolvimento das atividades dos futuros profissionais. A percepção de que a adubação orgânica é sustentável está ilustrada nas respostas do quadro 6.

Quadro 6: Opiniões dos estudantes sobre a indicação do uso da adubação orgânica na futura prática profissional.

\begin{tabular}{|c|c|}
\hline Entrevistados & Respostas dos estudantes que mais se destacaram \\
\hline Estudantes $2,11,41$ e 81 & "Por ser mais sustentável". \\
\hline Estudante 83 & "Pela preservação da natureza". \\
\hline Estudante 48 & "Trará benefícios ao meio ambiente". \\
\hline Estudante 79 & "Agride menos o meio ambiente". \\
\hline Estudante 59 & "Pois aproveita o solo e a natureza". \\
\hline Estudante 1 & "Porque iria ajudar no desenvolvimento do solo". \\
\hline Estudante 26 & "Menos prejudicial". \\
\hline Estudante 67 & "É Agroecológico". \\
\hline Estudante 44 & "Pois trará benefícios a propriedade". \\
\hline Estudante 91 & "Pelos inúmeros benefícios". \\
\hline
\end{tabular}

Essa visão que os estudantes têm sobre as vantagens de fazer uso da adubação orgânica como garantia para a sustentabilidade é importante, pois a produção orgânica é relevante para a manutenção do meio ambiente. Além disso, a adubação orgânica traz inúmeros benefícios à saúde, permite também que os alimentos cultivados se tornem bem mais resistentes às pragas e, consequentemente, contribuem para safras bem mais abundantes (ANDRADE et al., 2017). 


\section{CONCLUSÕES}

Frente aos conhecimentos evidenciados por parte dos discentes do curso de Agropecuária, cabe a seguinte reflexão: Será que os agricultores estão realmente realizando a tecnologia agrícola de adubação orgânica, mais sustentável para o meio ambiente e satisfatória para as plantas? Uma vez que foi constatado, através da fala dos estudantes, que serão futuros profissionais da área e auxiliarão os agricultores em campo, que os agricultores faziam uso da adubação, fosse ela química ou orgânica, mas sem orientação profissional e ainda apresentaram pouco conhecimento sobre o assunto.

Diante do despreparo de alguns profissionais dessa área permanece o questionamento de como as práticas do uso de fertilizantes são realizadas na região. Respostas, tais como, de fato, os agricultores da região de Apodi ou do semiárido nordestino veem a adubação orgânica, são necessárias para que sejam efetuados direcionamentos para as práticas sustentáveis na agricultura. Será que eles têm conhecimento suficiente para aplicar estas práticas em campo, se os futuros profissionais dessa área têm pouco conhecimento? Como eles irão auxiliar os produtores em campo? Faz-se necessária mais ênfase na formação desses discentes quanto a práticas agrícolas sustentáveis.

A percepção dos estudantes sobre a importância do uso dos dois tipos de fertilizantes e a preferência pela adubação orgânica foi positiva. Esta percepção alcança a reflexão sobre a adubação orgânica como agente minimizador da quantidade de resíduos usados nas propriedades, diminuindo os custos na compra de insumos agrícolas gerando benefícios econômicos e ambientais com a preservação do solo, e tornando o campo mais sustentável.

O conhecimento expresso pelos discentes sobre a importância de fertilizantes químicos para nutrição do solo, mas, prejudiciais à saúde humana, de outros animais e ao meio ambiente, traz uma nova perspectiva para a busca de práticas agrícolas mais sustentáveis. O desafio lançado à nova geração de profissionais da Agropecuária é repensar sobre o tema acerca da produção de espécies vegetais dentro de uma perspectiva sustentável. Solos e recursos naturais devem ser conservados para que seja garantido o bem-estar das gerações futuras.

\section{REFERÊNCIAS}

ABREU, P. H. B. B.; ALONZO, H. G. A.. Trabalho rural e riscos à saúde: uma revisão sobre o 'uso seguro' de agrotóxicos no Brasil. Ciência \& Saúde Coletiva, v.19, n.10, p.4197-4208, 2014. DOI: http://doi.org/10.1590/1413812320141910.09342014

ALMEIDA-NETO, M. G.; REIS, R. B. S.. Agrotóxicos em água para o Consumo Humano. Revista de Psicologia, v.10, n.33, p.274-282, 2016. DOI:

https://doi.org/10.14295/idonline.v10i33.621

ANDRADE, B. N.; FREITAS-PINHEIRO, J.; OLIVEIRA, E. M.. A importância da produção orgânica para a saúde humana e o meio ambiente. South American Journal of Basic Education, Technical and Technological, v.4, n.2, p.227-233, 2017.
ASSIS, R. L.; ROMEIRO, A. R.. Agroecologia e agricultura orgânica: controvérsias e tendências. Desenvolvimento e meio ambiente, n.6, p.67-80, 2002. DOI: http://doi.org/10.5380/dma.v6.22129

BAUER, M. W.; GASKELL, G.; ALLUM, N. C.. Qualidade, quantidade e interesses do conhecimento: evitando confusões. In: BAUER, M. W.; GASKELL, G.. Pesquisa qualitativa com texto, imagem e som. Petrópolis: Vozes, 2002. p.17-36.

BRASIL. Resolução $\mathbf{n} . \mathbf{5 1 0}$ de $\mathbf{0 7}$ de abril de 2016. Dispõe sobre as normas aplicáveis a pesquisas em Ciências Humanas e Sociais. Brasília: DOU, 2016. 
CAMARGO, M. S.. A importância do uso de fertilizantes para o meio ambiente. Pesquisa \& Tecnologia, v.9, n.2, p.1-4, 2012.

COSTA, D. D.; KEMPKA, A. P.; SKORONSKI, E.. A contaminação de mananciais de abastecimento pelo nitrato: o panorama do problema no Brasil, suas consequências e as soluções potenciais. Rede, v.10, n.2, p.29-61, 2016. DOI: http://doi.org/10.22411/rede2016.1002.04

DESSEN, M. A.; COSTA-POLONIA, A.. A família e a escola como contextos de desenvolvimento humano. Paidéia, v.17, n.36, p.21-32, 2007. DOI: http://doi.org/10.1590/s0103$863 \times 2007000100003$

FINATTO, J.; ALTMAYER, T.; MARTINI, M. C.; RODRIGUES, M.; BASSO, V.; HOEHNE, L.. A importância da utilização da adubação orgânica na agricultura. Revista Destaques Acadêmicos, v.5, n.4, p.85-93, 2013.

JARDIM, I. C. S. F.; ANDRADE, J. A.; QUEIROZ, S. C. N.. Resíduos de agrotóxicos em alimentos: uma preocupação ambiental global - um enfoque às maçãs. Química Nova, v.32, n.4, p.996-1012, 2009. DOI: http://doi.org/10.1590/s0100-40422009000400031

LEFF, E.. Complexidade, racionalidade ambiental e diálogo de saberes. Educação \& Realidade, v.34, n.3, p.17-24, 2009.

MAZOYER, M.; ROUDART, L.. Biomassa, solo e fertilidade. In: MAZOYER, M.; ROUDART, L.. História das agriculturas no mundo: do neolítico à crise contemporânea. São Paulo: EDUNESP, 2010. p.77-87.

MEKSENAS, P.. Pesquisa social e ação pedagógica. In: MEKSENAS, P.. Métodos em pesquisa empírica. São Paulo: Loyola, 2002. p.133-139.

MORALES, R. G. F.; FARIA, M. V.; RESENDE, J. T. V.; RISSINI, A. L. L.; CARMINATTI, R.; FARIA, C. M. D. R.. Produtividade do morangueiro em função da adubação orgânica complementar em cultivo protegido. Ambiência, v.8, n.1, p.23-33, 2012. DOI:

http://doi.org/10.5777/ambiencia.2012.01.02

PEDRO-JUNIOR, A.. Uso de micro-organismos da rizosfera para o aumento e melhoramento das colheitas. Mikarimin: Revista Científica Multidisciplinar, v.1, n.1, p.73-84, 2015.

PINHEIRO, F. W. A.; NOBRE, R. G.; SOUZA, L. P.; OLIVEIRA, S. G.; ARAÚJO, J. E. S.; VELOSO, L. L. S. A.. Irrigação com água salinas e adubação nitrogenada na produção de mudas mamoeiro 'formosa'. Revista Verde de Agroecologia e

Desenvolvimento Sustentável, v.12, n.1, p.17-22, 2017. DOI: http://doi.org/10.18378/rvads.v12i1.4754

RODRIGUES, J. C.; VILAR, C. C.; VILAR, F. C. M.; OLIVEIRANETO, A. M.; BOTTEGA, E. L.. Levantamento da utilização das recomendações técnicas quanto a amostragem de solo, calagem e uso de fertilizantes minerais no cultivo da soja, no município de Mato Rico-PR. Revista Campo Digit@I, v.10, n.1, 2015.

ROMUALDO, L. M.; LUZ, P. H. C.; BAESSO, M. M.; DEVECHIO, F. F. S.; BET, J. A.. Spectral indexes for identification of nitrogen deficiency in maize. Revista Ciência Agronômica, v.49, n.2, p.183-191, 2018. Dol: http://doi.org/10.5935/1806-6690.20180021

SANTOS, I. C. S.; COSTA, A. N.; MARTINS, H. F.; SOUSA, A. C.; SOUSA, L. A. S.. Agricultura familiar no quilombo de Abacatal: Os modos de produção são sustentáveis?. Cadernos de Agroecologia, v.10, n.3, 2016.

SEDIYAMA, M. A. N.; MAGALHÃES, I. P. B.; VIDIGAL, S. M.; PINTO, C. L. O.; CARDOSO, D. S. C. P.; FONSECA, M. C. M.; CARVALHO, I. P. L.. Uso de Fertilizantes orgânicos no cultivo de alface americana (Lactuca sativa L)'Kaiser'. Revista Brasileira de Agropecuária Sustentável, v.6, n.2, p.66-74, 2016.

SOUSA, G. G.; VIANA, T. V. A.; REBOUÇAS-NETO, M. O.; SILVA, G. L.; AZEVEDO, B. M.; COSTA, F. R. B.. Características agronômicas do girassol irrigado com águas salinas em substratos com fertilizantes orgânicos. Revista Agrogeoambiental, v.9, n.1, 2017. DOI: http://doi.org/10.18406/2316-1817v9n12017920

STAMATO, B.; MOREIRA, R. M.. Metodologias Participativas em Agroecologia: redes, processos e estratégias rumo a uma Pedagogia do Alimento. Redes, v.22, n.2, 2017. DOI: http://doi.org/10.17058/redes.v22i2.9347

VÉRAS, M. L. M.; MELO-FILHO, J. S.; ALVES, L. S.; IRINEU, T. H. S.; SILVA, G. G.; ANDRADE, R.. Influência da aplicação de urina de vaca em pimentão (Capsicum annuum L.) em função de adubos orgânicos. Revista agropecuária técnica, v.36, n.1, p.222-228, 2015. DOI: https://doi.org/10.25066/agrotec.v36i1.24736

VIEITES, R. G.. Agricultura sustentável: uma alternativa ao modelo convencional. Revista Geografar, v.5, n.2, p.1-12, 2010. DOI: http://dx.doi.org/10.5380/geografar.v5i2.20133

A CBPC - Companhia Brasileira de Produção Científica (CNPJ: 11.221.422/0001-03) detém os direitos materiais desta publicação. Os direitos referem-se à publicação do trabalho em qualquer parte do mundo, incluindo os direitos às renovač̃os, expansões e disseminaç̃es da contribuiç̃o, bem como outros direitos subsidiários. Todos os trabalhos publicados eletronicamente poderão posteriormente ser publicados em coletâneas impressas sob coordenação da Sustenere Publishing, da Companhia Brasileira de Produção Científica e seus parceiros autorizados. Os (as) autores (as) preservam os direitos autorais, mas não têm permissão para a publicação da contribuição em outro meio, impresso ou digital, em português ou em tradução. 